\title{
IMPROVING EFFICIENCY OF COURTS AND OTHER INSTITUTIONS BY SMART AV RECORDING SYSTEM
}

\section{Dragan Vujovic}

Sustainable Development Management, The University "Union - Nikola

Tesla", Belgrade, Serbia

https://orcid.org/0000-0002-3785-4929

\section{Aleksandar Gracanac}

Faculty of Entrepreneurial Business and Real Estate Management, The University "Union - Nikola Tesla", Belgrade, Serbia

https://orcid.org/0000-0002-3018-2912

\section{Andrej Spirkovski}

Faculty of Business in Belgrade, Singidunum University, Belgrade, Serbia https://orcid.org/0000-0001-8136-5666

OMESTE

JEL Category: $\mathbf{H 8 3}, \mathbf{0 3 3}$

\begin{abstract}
The right to a fair trial is at the top of the human rights hierarchy in all democracies. In the past, primarily due to a lack of modern technical solutions that are available today, it was difficult to ensure a fair trial, as well as to check the correctness of the decision made in the courtroom if necessary. Today, audio/video recording of the court hearings is implied in many developed countries worldwide, precisely because of the transparency of the processes in which important decisions concerning human rights and freedoms are made, all with the goal of justice being absolutely and uncompromisingly served. The goal of this research is to present the solution for the development and integration of a secure and accessible ICT smart system primarily intended for recording court hearings, but also recording for any established legal institutions that need for it, such as prosecutors' offices, police stations, social work centers, shareholders' assemblies, notary offices, etc. As far as joint-stock companies are concerned, such a system would ensure the necessary transparency in companies and facilitate the successful implementation of all other elements of corporate governance.
\end{abstract}

Keywords: Court Hearing, recording, corporate governance, ICT, fair trial

\section{INTRODUCTION}

Address of the corresponding author:

Dragan Vujovic

D伟dragangagivujovic@gmail.com
The Law on Ratification of the European Convention for Protection of Human Rights and Basic Freedoms which was signed on November 
4, 1950, in Rome and ratified in Serbia and which was adopted to protect human rights and basic (fundamental) freedoms, as the very title reads, among other things, refers to the Right to Fair Trial (Council of Europe, 1950). To have a truly fair trial and not to impair the basic human rights of affected parties within the judicial proceeding, it is also necessary to make a video and audio recording of the court hearing. Nowadays, when whole cities are covered with video surveillance systems and when cameras cover public areas, streets, and squares to provide a higher level of security for citizens and to prevent law disobedience and record cases of law violations, it is illogical not to implement such systems in areas where final decisions are made on whether the law was truly violated, where human destinies are decided on and where justice is enforced, i.e. in the courtroom. The judicial system cannot and must not stay aside from technological progress in all social spheres (Fabri \& Contini, Justice and Technology in Europe: How ICT is Changing Judicial Business, 2001). In addition to the necessity of system efficiency, justice must be available while citizens must be aware that it was served (Andrade \& Joia, 2012). As early as October 25, 2018, the Belgrade Bar Association $(A K B)$ requested amendments of the Criminal Procedure Code and Civil Procedure Code to enable mandatory sound recording of all trials in Serbia and they announced that they would file an initiative to the Ministry of Justice which was filed on December 4, 2019. However, no further steps were made. Regarding the criminal procedure, the authority conducting proceedings may adopt a decision to record the evidentiary action or other actions via devices for sound or optical recording, but the sound recording of defendants and witness and expert witnesses questioning within the procedure is obligatory only for criminal offenses referred to in a specific Code article (National Assembly of the Republic of Serbia, 2019). With regards to civil procedures, either ex officio or upon an affected party proposal, the Court may adopt a decision to have sound or optical recording of the hearing (National Assembly of the Republic of Serbia, 2020), and, therefore, in most cases, it is legally possible to record a court hearing, but it is necessary to implement the system to make it technically viable. The Law prescribes drafting a record where only important content of the given statements is included and all that only in the form of narration which entitles the court to retell and paraphrase the statements of affected parties and witnesses in a manner recordkeepers understood and heard them. It is very easy to misuse this right in practice since, by paraphrasing, the statements, details which are seemingly unimportant while they are crucial are lost in the further trial. The introduction of a smart system for optical and sound recording of court hearings would remove the possibility for accidental or intended misuse during the record drafting procedure while court hearings would take fairly less time and a possibility to have a higher court efficiency would be created. Regarding corporate governance, for sure it has an important role in the sphere of management, and the investigation of occurrences resulting from corporative management require a definition among which the most famous would be the one from the Cadbury Report which indicates that corporate governance is the system where companies are directed and controlled (Cadbury, 1992). While Serbian corporate governance is on a decent level in companies owned by foreign companies, for sure there is plenty of room for progress in locally-owned companies. The introduction of such control systems would accelerate the transition to corporate governance considerably and it would upgrade the communication between shareholders' groups and the controlling shareholder, i.e. of the company management.

\section{INNOVATIVE TECHNOLOGICAL SOLUTION}

The implementation of the ICT solution into the judicial system should bring not only a higher efficiency of the system, but it should open the door for potential further innovations (Fabri, 2009). An innovative technological software and hardware solution has to be primarily reliable, efficient, and user-friendly. The idea is to make the technology mobile, easy to be installed and, in such a way, it should represent a comprehensive solution for digital recording of court procedures, e.g. interrogations in the police and the prosecution office. The solution also has to be 
affordable in the financial sense since technological solutions offered by foreign companies are very expensive. It should be particularly noted that those solutions also bring problems that stem from the technology and which are overcome in the solution presented in the paper. Those solutions which have been known so far face problems with synchronizing streaming of video databases from cameras and audio databases from microphones. In practice, it means that there is a time gap between the video and the sound of one to three seconds which creates a big problem during the recording reproduction. Calibration is performed during, in this case necessary, post-production which implies an additional use of time during the hearing. During this period which approximately lasts 20 minutes, during which post-production is performed (synchronization of video and audio recording), the hearing room is occupied and another hearing cannot be held which is why, in case this solution is implemented, the possibility to save time and increase the productivity of the whole system is completely missed. Lawyers, prosecutors, and judges also have to wait for this process to end. If multiplexing of audio and video channels with encryption and compression is not done in real-time for a hearing which lasted e.g. 60 minutes, further processing (processing, compression, and encryption) could take even over 30 minutes which means that the copy of the recording could be available to affected parties only 30 minutes after the end of the hearing. In line with the provisions of the Civil Procedure Code, a copy of an audio and video recording must be submitted to affected parties immediately upon the session. Since audio and video recording from hearings in case of this innovative solution is created in real-time, it is available to participants in a digital medium (e.g. USB stick, the link for download, etc.) immediately upon the end of the hearing.

In the case of the innovative techniques presented in this paper, many problems faced with the existing technological solutions do not exist. The technology is based on SIP protocol which is also used in telecommunications for VolP conferences and IP telephony, where SIP protocol ensures the compression in real-time and multiplexing of audio/video channel/databases. This smart and secure multi-channel $A / V$ recording system includes several additional innovations. Since it is necessary to comply with the rights of protected witnesses, minors, and other persons whose identity should be hidden in line with the law, all audio recordings of the above-mentioned persons are scrambled in real-time which is why it is impossible to recognize the identity of the speaker. The voice is motorized but it remains completely understandable to a listener and a part of the video recording is blurred. During this process, not one important segment of the recorded material is lost. Such systems are used in some countries for hearings of prisoners or protected witnesses which are in safe locations (Bailey, 2012).

The Civil Procedure Code reads that the hearing recording must also include the court title and the court composition, venue, date and time of the hearing, dispute subject and names of affected parties and other persons as well as of their legal representatives and plenipotentiaries. In addition, it has to include the data on the identity of persons whose statement is being recorded and their role in the procedure. In cases when statements of several people are recorded, the recording must provide a clear understanding of which person gave the statement. This technological solution enables these data to be included as an audio statement in an audio recording, in contrast to the solutions which have been used so far where such information had to be inserted as a title of a video database. This is very important because audio recordings are mobile phone-friendly which is why this solution is more convenient since it is generally accepted practice for judges to listen to audio recordings for days before the adoption of the final verdict. Since all the necessary information is included in the audio recording in case of this technological solution, it enables the listener with authorized access to follow the course of the hearing without any problems because the audio database with the above mentioned necessary information which is in this case given at the beginning of the audio database, also includes the information about the person who is speaking at that moment (e.g. 14:41, the judge Mitrovic is speaking). 


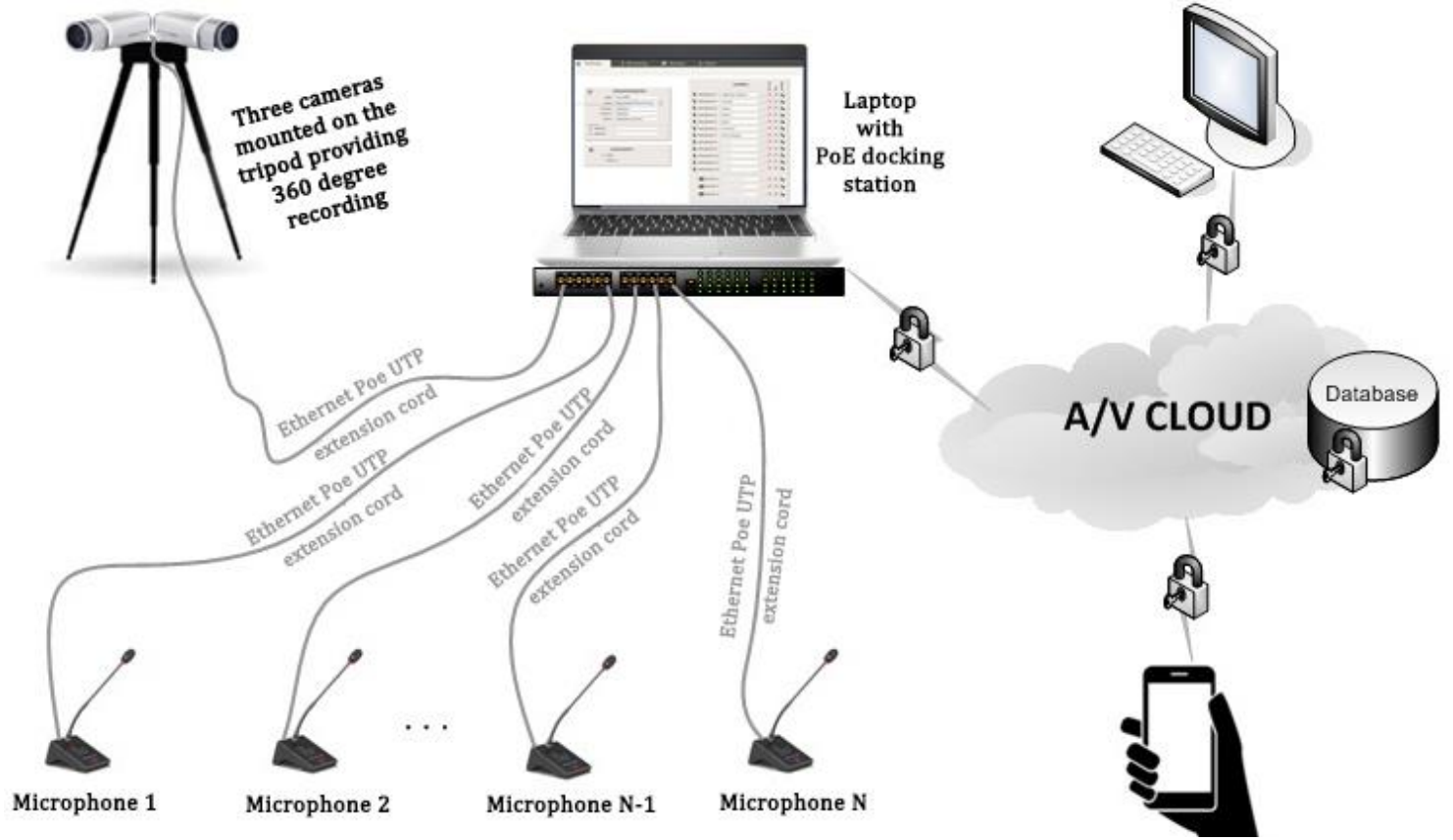

Figure 1. Scheme of the system for audio and video recording of hearings

Another innovation in such systems would be smart microphones adjusted to the specific needs of end-users. Smart microphones would compress the audio databases locally on the microphone, instead of doing this on the laptop which enables a less time-consuming subsequent processing for the audio recording. This would reduce the time for subsequent processing of audio and video recording since all authorized participants would be enabled to save their databases on USB memory at the same time. All these smart microphones would include a USB connector on the front side by which users (judges, lawyers, defendants, prosecutors, etc.) can download the audio recording of the hearing on their USB memory.

It is important to stress that this system would enable modular and very simple installation via only Ethernet communication cables and $\mathrm{PoE}$ (Power over Ethernet) system

All microphones, cameras, and other specific equipment are SIP clients and they are connected to an audio/video conference via soft switch (FreeSWITCH - freeswitch.org). The safety of the system is crucial in these projects which is why the idea is to have a system for databases coding which enables access to private recordings exclusively to persons who were given this access by the decision of the judge which is a common practice in both local and international judicial systems. All courts and other entities may search through notes and recordings with a strong mechanism for identity confirmation and protection on the web portal. Persons with authorized access will be in a position to watch the recordings via desktop computers, laptops, and mobile phones.

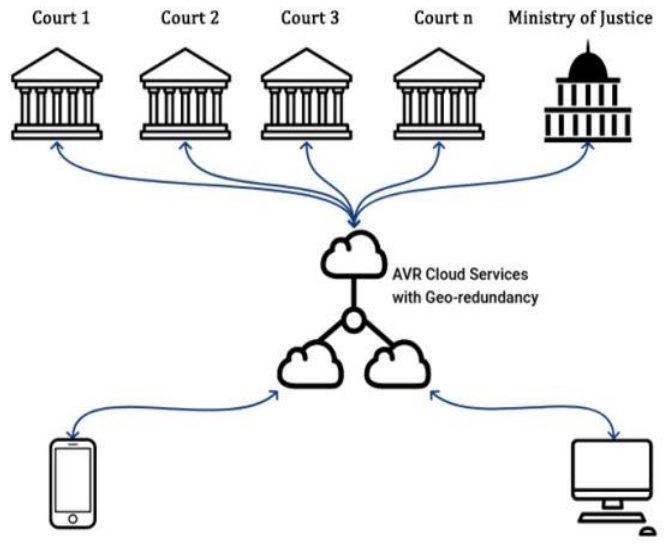

Mobile phone application

Computer application

Figure 2. Availability of audio and video recordings and documents via cloud service

\section{ICT SYSTEM COMPONENTS AND SPECIFICATIONS}

The components of this smart system are the master unit (local server), central server, judge (master) audio unit, and audio (microphone) unit of a participant (slave). 
The master unit (local server) includes software that enables system management and administration in the courtroom. The use of this software requires the authentication of users by the use of eligible electronic certificates of the Republic of Serbia. The master unit includes the following hardware components:

- Motherboard.

- Processor.

- HDD.

- Power unit.

- RAM.

- Accompanying electronics.

- Ethernet 10/100/1000 BaseT connection.

- $5 \times$ RJ-45 FTP connector (concentrator of the signal from audio units).

- Monochromatic touch screen (used for interaction during audio recording on a USB stick and other control operations).

- USB connector which provides for recording and notes download during the session with the permission of an authorized system user (role) on the USB memory stick.

- AUX audio output for forwarding audio signal which is currently recorded to an external amplifier.

- Possibility to assemble it to the wall or a desk.

- etc.

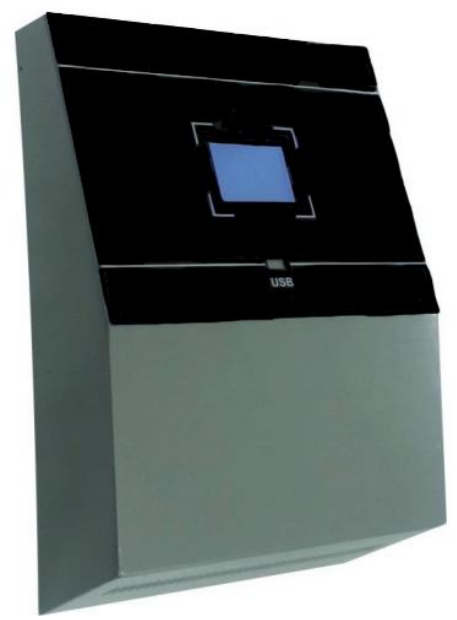

Figure 3. Master unit (local server)

As far as the functionality is concerned, this software includes at least:

- The functionality of the software in the system is individually enabled to user roles.

- All functionalities enable the use of the master unit instead of the audio unit of the judge.
- Definition of users, their cards, and user roles (judge, stenographer, etc.) in the system.

- Definition of data on the trial which is being recorded: Hearing Title, File Number, Trial Participants with Roles (Prosecutors, Defendants, Lawyers, Witnesses, etc.), Audio/Video Recording Access/Listening Rights, etc.

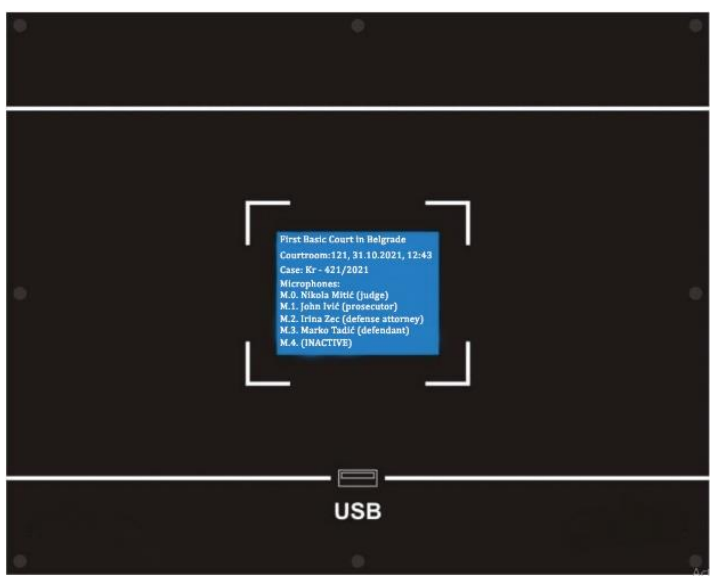

Figure 4. Master unit user interface

- Definition of parameters of system operations on the session: Via web browsers, the data defining the trial are inserted: file number, procedure participants (judge, affected parties, lawyers, witnesses, etc.); Persons entitled to listen to the audio recording of the given hearing are defined; Definition of an audio introduction on trial participants (sound identifier is recorded for each microphone by the use of microphone and web browsers and it is inserted into the sound recording in line with the principle "12.46, lawyer Petar Petrović is speaking..."

- Drafting and creation of the hearing record.

- Activating recording and inserting notes related to the time in the recording by a stenographer.

- Digital signing of recorded audio/video files (protection of possible subsequent corrections by third parties) enables audio/video recordings to be used as evidence material in judicial proceedings.

- Noting time information on the active microphone, i.e., on the trial participant which was given the floor during hearing recording and noting parts of recording acknowledge as important by the judge. 
- Listening/watching the recordings with - Etc. indicated related notes at a certain point of time within a recording with a possibility to start listening/watching those moments by choosing them from the list of notes.

All authorized users will be enabled by the central server to watch, listen and download recorded trial material via the internet, via standard web

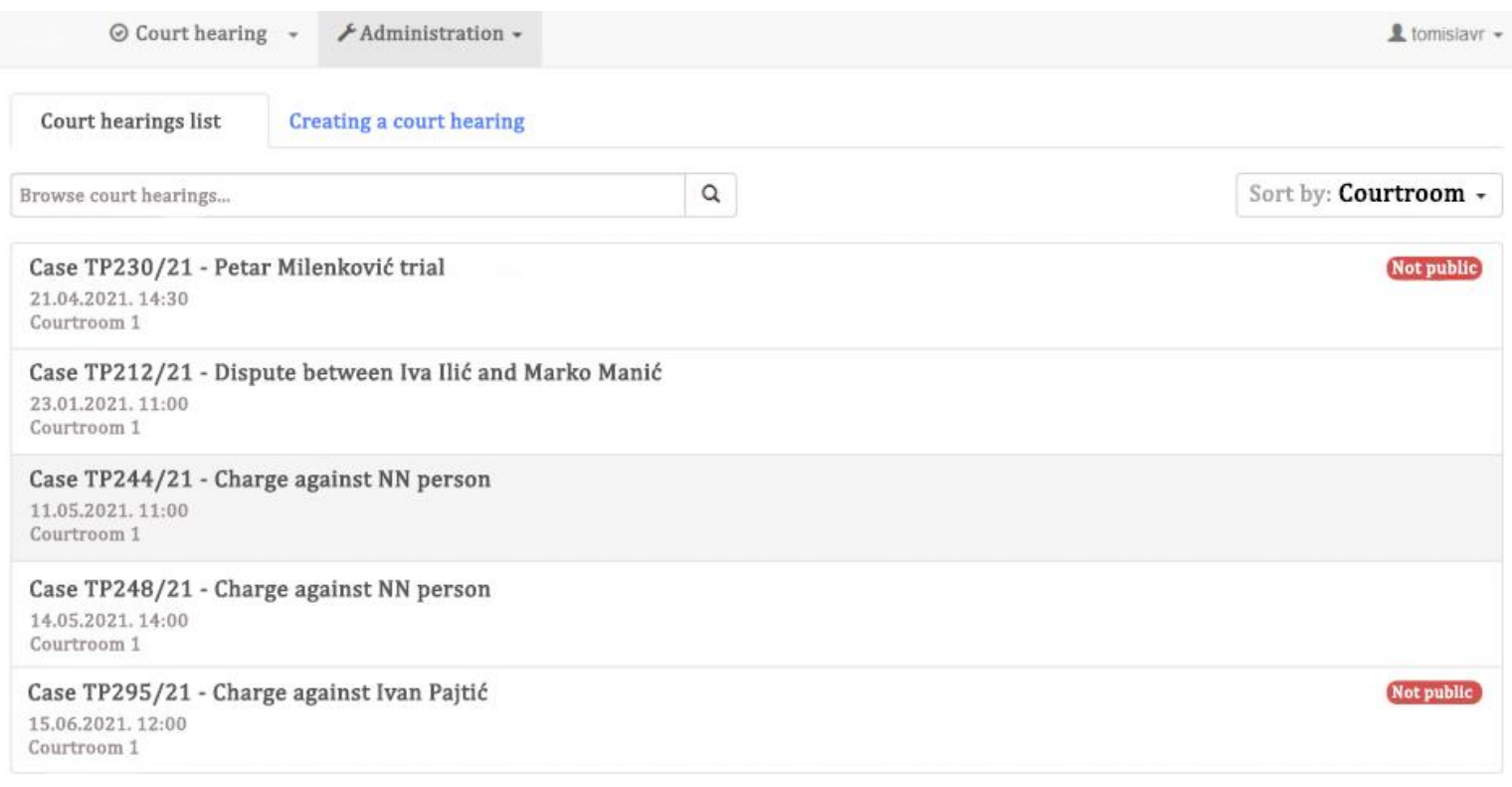

Click on the hearing you wish to review in detail

Figure 5. Software solution example 1

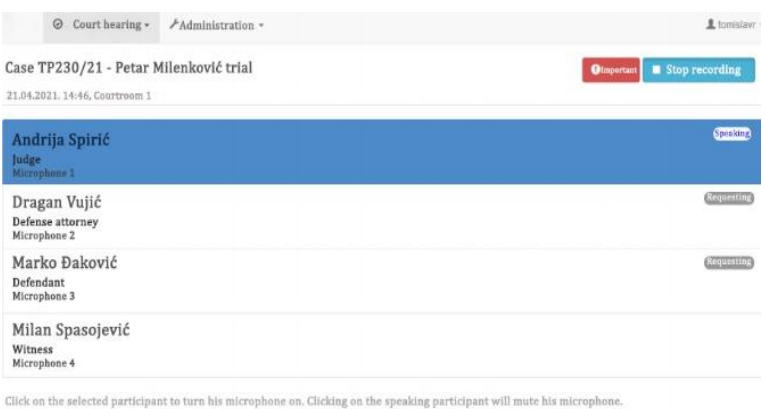

Figure 6. Software solution example 2

- Listening/watching only important parts of the recording or parts with related notes.

- Listening of the recording with inserted sound introductions before a participant's involvement.

- Possibility to listen to the parts of recordings described in the $7^{\text {th }}, 8^{\text {th }}$, and $9^{\text {th }}$ bullet via the use of a web browser and enabling web access with certificate authorization to the authorized system users.

- Activating USB connection where USB stick can be inserted which is used for downloading audio recording with anti-virus protection.

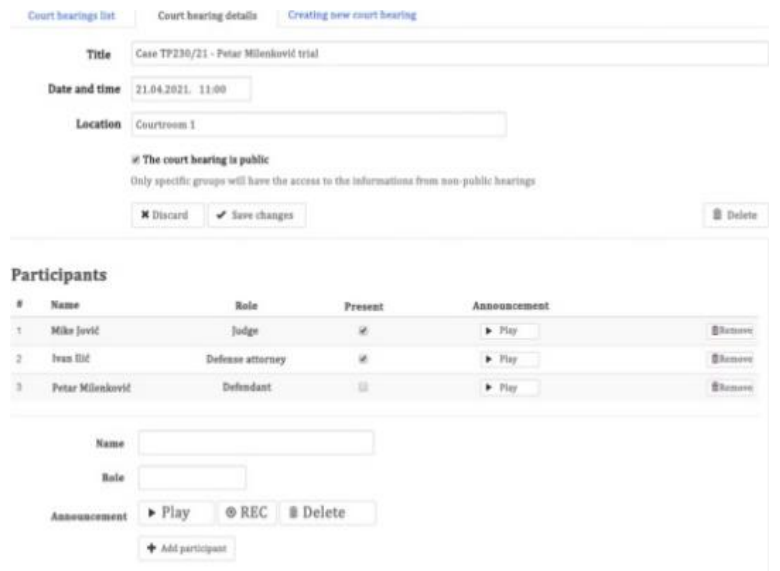

Figure 7. Software solution example 3

browsers. Listening is considerably facilitated byvisual and sound signaling to make it clear who is speaking at the given moment. Uses who need remote access to audio recordings will have to sign in either via eligible electronic certificates of the Republic of Serbia or via logging in by their username and a code. The access to the central server which is in this case in a demilitarized zone of the Ministry of Justice of the Republic of Serbia is provided via the internet by logging in and with 
encryption, via eligible electronic certificates which are used on the territory of the Republic of Serbia.

The judge (master) audio unit enables the judge to manage all audio units of participants and basic system operations. The Judge audio unit includes:

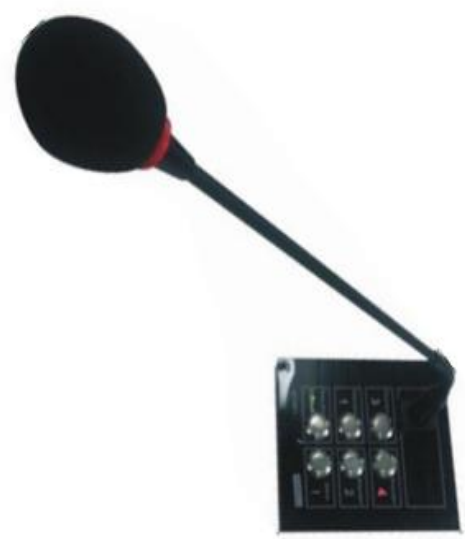

Figure 8. Judge unit with a microphone

- Professional microphone.

- The speaker emitting the sound from the microphone which is currently active (the microphone from which the sound is currently being recorded).

- Potentiometer for volume up/down of the speaker.

- Monochromatic touchscreen or 4 metal antivandal buttons activate microphone units of participants where each button is marked with an ordinal number (1-4) with background LED lighting which indicates the status of the microphone unit of a participant.

- Button marking a segment of the session which is particularly important (if marked "important", the trial segment is signalized by red background LED lighting behind a big "!" mark).

- Button for activating/deactivating the judge microphone unit.

- On/off switch for turning on and turning off the recording system.

- FTP RJ-45 connection for connecting by FTP cable to a central master unit (local server). Since the microphone is placed on a metal holder, it is necessary to provide adequate grounding of the audio unit by a metal shell of the FTP cable.

The buttons on audio units are anti-vandal (metal) and their function is properly marked with clear and visible signalization of the state of the action performed by the button. Background LED lighting provides information on the activities of participants' (slave) audio units to the judge via different colors. The green background light marks that the microphone under that ordinary number is active and that the signal from that microphone is being recorded. The red background color marks that the microphone under that ordinary number is inactive. The red blinking light marks that the microphone under that ordinary number asked to take the floor. The lack of the background light marks that the microphone under that ordinary number is turned off.

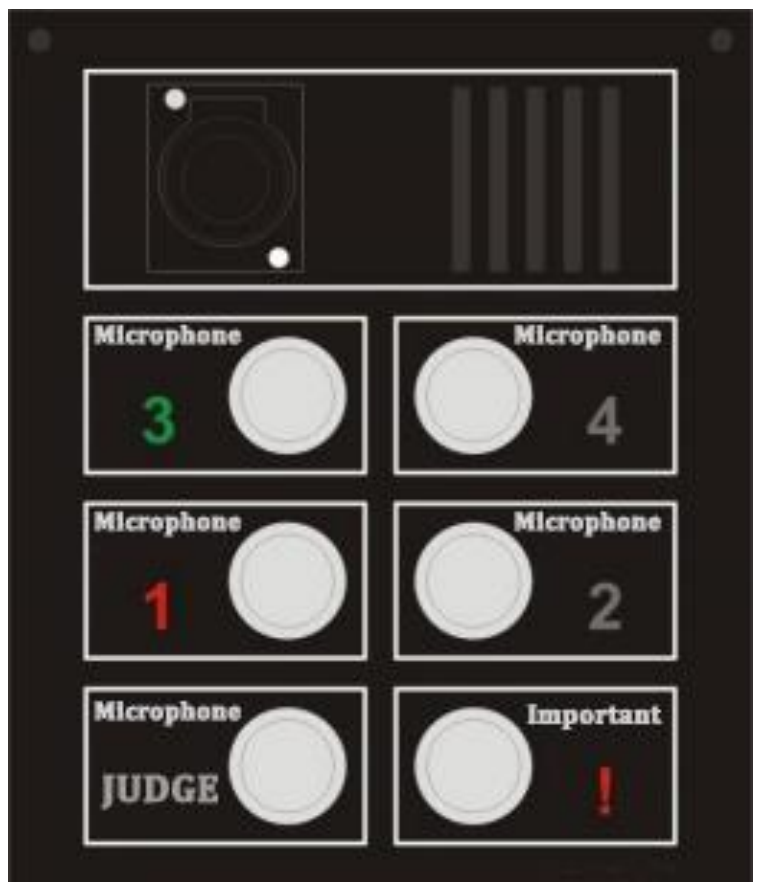

Figure 9. Judge master unit

The audio (microphone) participants' (slave) unit has a button for notifying the control microphone judge unit on a request to take the floor and a speaker emitting the sound from the microphone of the unit when the unit is active. The button on the unit has to be mechanical, its function has to be properly marked and the state of the action which the button performs has to be signaled. The unit includes:

- Professional microphone.

- The speaker emitting the sound from the microphone which is currently active (the microphone from which the sound is currently being recorded).

- Potentiometer for volume up/down of the speaker. 
- One metal anti-vandal button enables a participant to ask to take the floor i.e., sends a request (or annuls the request).

- LED background lighting indicates the status of the microphone unit.

- On/off switch for turning on and turning off the microphone unit.

- FTP RJ-45 connection for connecting by FTP cable to a central master unit (local server). The same as with the judge's unit, the microphone is placed on a metal holder, which is why it is necessary to provide adequate earthing of the audio unit by a metal shell of the FTP cable here as well.
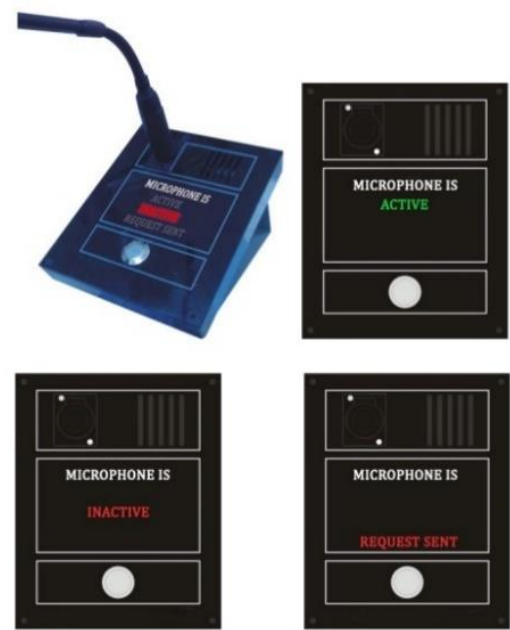

Figure 10. Participants` audio unit (slave)

The LED lights principle functions the same as on the judge master unit. The green background light (ACTIVE) marks that the microphone is active and that the signal from this microphone is being recorded. The red background color (INACTIVE) marks that the microphone under that ordinary number is inactive while the red background light under the title "REQUEST SENT" marks that the participant sitting by the microphone under that ordinary number asked to take the floor.

\section{SYSTEM APPLICABILITY IN THE REPUBLIC OF SERBIA}

Primarily, this solution would be implemented with all legal institutions which require automation of trial/hearing records and where it is necessary to have a $100 \%$ correlation between the audio/video recording and the record. The system would be implemented in courts, prosecution offices, police stations, social work centers, joint-stock companies' shareholders' assemblies, notary offices, etc. The system is also designed to serve as a video and audio conference system which can be used as a communication channel for remote witness hearing which is very important for witnesses such as minors, people with disabilities, old people, and witnesses in prisons. It would be important to implement the system in courtrooms and hearing rooms in the police and the prosecution office. Securing the transparency in these institutions is necessary to exercise the given right to a fair trial. Free recording service in cases of criminal proceedings for offenses for which it could be required to serve less than 5-7 years is the general practice in democratic societies and, in this case, the state bears all costs of audio and video recordings. With criminal proceedings for offenses for which it could be required to serve longer than 5-7 years and for those convicted as well as in cases of civil proceedings, the recording cost should be borne by one of the proceeding participants which should be considered as legal costs which should be compensated depending on the decision of the judge. There are 159 courts in the Republic of Serbia (with between 5 and 25 courtrooms), twice as high a number of police stations with 1-3 interrogation rooms and 83 public prosecution offices (each with 3-5 hearing rooms). The system implementation in each of the given institutions would represent a high cost at the beginning. The solution for a successful implementation of this system in practice would be the establishment of the Chamber of Authorized Recorders which would function according to a similar model as e.g. the Chamber of Bailiffs or Notaries. In addition, it is necessary to create a portal for recording booking. All court procedure parties should be provided with a possibility to book/notify in advance that they would like to have audio and video recordings of the court procedure on the booking portal. The party who expressed their interest in audio and video recording of the court proceedings should pay the recording costs in advance and these funds would be referred to as "court expenditure". Those costs should be compensated to the affected party if the party turns out to be the prevailing one in a similar manner as it is done with the lawyer expenditure at the end of the trial. Average recording costs should amount to $40 \%$ of the lawyer costs indicated in the price list of the Bar Association of Serbia. 


\section{CONCLUSIONS}

The smart ICT solution presented in this paper would settle numerous problems faced by the judicial system as well as by the citizens of the Republic of Serbia. The crucial thing is that, in the first place, the implementation of this system would provide for the respect of fundamental human rights and secure the transparency of judicial procedures which would increase the trust in state institutions of the citizens of the Republic of Serbia. Courts productivity would be also increased considerably since the problem faced during the use of other systems related to the synchronization of audio and video recordings would be solved. The implementation of this system would secure the increase in the number of trials on the annual level and the correctness of reached verdicts could be checked easily by watching, listening, and analyzing the recordings and the discussions on who said what and when would be a matter of the past.

\section{WORKS CITED}

Andrade, A., \& Joia, L. A. (2012). Organizational structure and ICT strategies in the Brazilian Judiciary System. Government Information Quarterly. 29. 10.1016/j.giq.2011.08.003.

Bailey, J. (2012, October 23). Digitization of Court Processes in Canada. Laboratory of Cyberjustice Workin Paper $n^{\circ} 2$.

Cadbury, A. (1992). Report of the Committee on the Financial Aspects of Corporate Governance. London: Gee and Co Ltd.

Council of Europe. (1950). European Convention for the Protection of Human Rights and Fundamental Freedoms In Council of Europe Treaty Series 005. Council of Europe. https://www.refworld.org/docid/3ae6b3b04.html

Fabri, M. (2009). E-justice in Finland and in Italy: enabling versus constraining models. Palgrave Macmillan UK.

Fabri, M., \& Contini, F. (2001). Justice and Technology in Europe: How ICT is Changing Judicial Business. Kluwer Law International.

National Assembly of the Republic of Serbia. (2019). CRIMINAL CODE. "Official Gazette of the Republic of Serbia", No. 72/2011, 101/2011, 121/2012, 32/2013, 45/2013, 55/2014 and 35/2019.

National Assembly of the Republic of Serbia. (2020). CIVIL PROCEDURE CODE - Decision of the Constitutional Court, 74/2013 - Decision of the Constitutional Court, 55/2014, 87/2018, and 18/2020). Official Gazette of the Republic of Serbia", No. 72/2011, 49/2013.

Received for publication: $\quad 27.05 .2021$

Revision received: $\quad$ 07.06.2021

Accepted for publication: $\quad 06.07 .2021$

\section{How to cite this article?}

Style - APA Sixth Edition:

Vujovic, D., Gracanac, A., \& Spirkovski, A. (2021, July 15). Improving efficiency of courts and other institutions by smart AV recording system. (Z. Cekerevac, Ed.) MEST Journal, 9(2), 81-90. doi:10.12709/mest.09.09.02.12

Style - Chicago Sixteenth Edition:

Vujovic, Dragan, Aleksandar Gracanac, and Andrej Spirkovski. 2021. "Improving efficiency of courts and other institutions by smart AV recording system." Edited by Zoran Cekerevac. MEST Journal (MESTE) 9 (2): 81-90. doi:10.12709/mest.09.09.02.12. 
Style - GOST Name Sort:

Vujovic Dragan, Gracanac Aleksandar and Spirkovski Andrej Improving efficiency of courts and other institutions by smart AV recording system [Journal] // MEST Journal / ed. Cekerevac Zoran. Belgrade - Toronto : MESTE, July 15, 2021. - 2 : Vol. 9. - pp. 81-90.

Style - Harvard Anglia:

Vujovic, D., Gracanac, A. \& Spirkovski, A., 2021. Improving efficiency of courts and other institutions by smart AV recording system. MEST Journal, 15 July, 9(2), pp. 81-90.

Style - ISO 690 Numerical Reference:

Improving efficiency of courts and other institutions by smart AV recording system. Vujovic, Dragan, Gracanac, Aleksandar and Spirkovski, Andrej. [ed.] Zoran Cekerevac. 2, Belgrade - Toronto: MESTE, July 15, 2021, MEST Journal, Vol. 9, pp. 81-90. 